\title{
Comparative Assessment of the Analgesic Efficacy of Tramadol and Diclofenac Sodium Rectal Suppository in Subjects Undergoing Laproscopic Tubal Ligation
}

\author{
Ushma K Baranda', Sheetal K Baranda ${ }^{2}$, Mikita Chaudhary ${ }^{1}$ \\ ${ }^{1}$ Assistant Professor, Department of Anaesthesiology, NHL Municipal Medical College Ahmedabad, Gujarat, India, ${ }^{2}$ Assistant Professor, Department of \\ Anaesthesiology, GCRI, Civil Hospital, Ahmedabad, Gujarat, India.
}

\section{Abstract}

Background: Several drugs such as NSAID s or opiods can be used orally, intravenously or intramuscularly for treatment of post operative pain. The aim of our study was to compare the analgesic efficacy of tramadol and diclofenac sodium suppository and the secondary aim was to monitor and treat the complications if any. Subjects and Methods: Fifty female patients of ASA I and II in the age group of 24-42 posted for laproscopic tubal ligation were enrolled in the study. Verbal analogue scale (0- no pain to 10- worst possible pain) score reading was explained. In the pre operative room all the patients were randomly allocated in two groups by a computer generated list. Post operatively all the hemodynamic parameters and VAS score were recorded at regular intervals of 1, 2, 4, 6, 8, 10,12hrs. Pain was assessed by a staff trained to VAS score assessment and was blinded to the study group. Side effects of nausea and vomiting were noted. Results: Group 2 had high mean age of the study participants compared to group 1 but the comparison was non-significant.(p $\leq 0.05$ ) Only one patient in group A (tramadol) complained of nausea and vomiting. In group A 69\% patients needed 1 rescue analgesic at $8 \mathrm{hrs}, 11 \%$ at $6 \mathrm{hrs}, 9 \%$ at $4 \mathrm{hrs}$ and $11 \%$ at $10 \mathrm{hrs}$ whereas in group B $64.1 \%$ patients needed 1 rescue analgesic at $8 \mathrm{hrs}, 16.2 \%$ at $10 \mathrm{hrs}$ and $19.7 \%$ at $12 \mathrm{hrs}$. Conclusion: From above findings it was concluded that analgesic efficacy of tramadol and diclofenac sodium suppository is comparable. Rectal administration of tramadol reduces the incidence of nausea and vomiting.

Keywords: Diclofenac sodium, Hemodynamic parameters, Nausea, Tramadol.

Corresponding Author: Dr. Sheetal K Baranda; Dept. of Anaesthesiology, GCRI, Civil Hospital, Ahmedabad, Gujarat, India.

Received: April 2019

Accepted: May 2019

\section{Introduction}

Laproscopic sterilization is a very common procedure performed in India. It is much more painful than diagnostic laproscopy. Davis and Millar studied that pain after lap sterilisation was much more than 1 diagnostic laproscopy during the first four post operative hours. In India the method used for sterilization is by using Fallop rings. Application of Fallop rings is associated with greater lower abdominal pain may be because of excessive traction on mucosa 2 and nerve fibers. Pain is an unpleasant sensory and emotional experience of varying intensity, caused by actual or potential damage or described in such type of damage.

Several drugs such as NSAID s or opiods can be used orally, intravenously or intramuscularly for treatment of post operative pain. Tramadol hydrochloride is a centrally acting opioid analgesic, which acts on mu opioid receptors, and is classified as a phase II analgesic according to the WHO pain score. ${ }^{[1]}$ Tramadol is an analgesic with mixed opioid and nonopioid activities. ${ }^{[2,3]}$ The nonopioid component is mediated through alfa- 2 agonist and serotonergic activity, which it exerts by inhibiting the reuptake of norepinephrine and 5-hydroxytryptamine in the central nervous system and possibly by displacing the stored 5-HT from the nerve endings. ${ }^{[4-8]}$

Tramadol is well tolerated by patients. Compared to morphine, tramadol has much less respiratory depression, cardiac depression, light headedness and sedative effect. Also addiction and abuse is much less with tramadol. ${ }^{[9-11]}$ The only troublesome side effect of tramadol is nausea and vomiting. That can be prevented by antiemetic drugs. ${ }^{[12,13]}$ Tramadol is available in all formulations i.e. oral, injectable and rectal. Tramadol used by different routes such as intravenous, intramuscular, rectal or local infiltration etc. have analgesic efficacy with different duration and variable incidence of side effects. ${ }^{[14-17]}$ However, after i.v. and oral administration, peak concentrations are reached rapidly, and this has been associated with postoperative nausea and vomiting. Rectal administration of tramadol may be an alternative in this situation. It is convenient to use and is the established treatment for postoperative pain in adults. It is important to stress that rectal absorption of tramadol showed a low variability. Diclofenac sodium is a tried and tested known NSAID very well effective for post operative pain. It can be given intravenously, intramuscularly or rectally. Dose 
may be adjusted as per intensity of pain in the range of 1$1.5 \mathrm{mg} / \mathrm{kg}$.

Rectally administered drugs have greater bioavailability as more than $50 \%$ are absorbed directly into general circulation bypassing the liver. It also avoids the gastric irritation caused by oral drugs and avoids 4 the pain of needle prick in intramuscular route. With above background in mind we decided to compare rectal tramadol with standard analgesic diclofenac suppository. The aim of our study was to compare the analgesic efficacy of tramadol and diclofenac sodium suppository and the secondary aim was to monitor and treat the complications if any.

\section{Subjects and Methods}

Fifty female patients of ASA I and II in the age group of 2442 posted for laproscopic tubal ligation were enrolled in the study. Ethical approval was taken from the institutional ethical committee and written informed consent was taken from all of the participants. According to power $80 \%$ of the study sample size achieved was 50. Any patient of ASA III and above, having systemic diseases and undergoing MTP with tubal ligation were not included in the study.

Routine investigations such as complete haemogram, urine routine, chest Xray, ECG, coagulation profile were carried out. All the patients were visited preoperatively and informed about the procedure and the Verbal analogue scale (0- no pain to 10-worst possible pain) score reading was explained. In the pre operative room all the patients were randomly allocated in two groups by a computer generated list In the operating room all the monitors including HR, NIBP, ECG, etCO2 were attached. $20 \mathrm{G}$ intravenous cannula was secured. Patients were premedicated with inj glycopyrolate $0.2 \mathrm{mg}$, midazolam $1 \mathrm{mg}$, ondensetron $4 \mathrm{mg}$, pentazocin $30 \mathrm{mg}$ intravenously. Group A patients received tramadol suppository while patients in Group B received diclofenac suppository. It was introduced in lithotomy position after administration of premedication. Induction was done using inj thiopentone sodium $5-7 \mathrm{mg} / \mathrm{kg}$ and inj succinylcholine $2 \mathrm{mg} / \mathrm{kg}$. Airway was secured using portex endotrachel tube. Vecuronium bromide was given as the long acting muscle relaxant $(0.08-0.1 \mathrm{mg} / \mathrm{kg})$. General anaesthesia was maintained with $50 \% \mathrm{O} 2$ in $\mathrm{N} 2 \mathrm{O}$ with Sevoflurane (0.6$0.8 \%$ ). Tubal ligation in all patients was done by application of Fallop rings. Intraoperatively all the vital parameters including heart rate, Spo2, end tidal $\mathrm{CO} 2$ and blood pressure (NIBP) were monitored and recorded every 5 mins. All patients received ringer lactate intravenously as per standard calculation. Extubation was done after thorough suctioning and reversing the neuro muscular blockade with neostigmine $0.5 \mathrm{mg} / \mathrm{kg}$ and glycoprolate $0.04 \mathrm{mg} / \mathrm{kg}$.

Post operatively all the hemodynamic parameters and VAS score were recorded at regular intervals of $1,2,4,6,8$, $10,12 \mathrm{hrs}$. Pain was assessed by a staff trained to VAS score assessment and was blinded to the study group. Side effects of nausea and vomiting were noted. Diclofenac sodium 75 mg intramuscularly was given as the rescue analgesic when the patients complained of VAS $>3$. Post operative nausea and vomiting was treated with inj ondensetron $4 \mathrm{mg}$ intravenously.

\section{Statistical analysis:}

The recorded data was compiled and entered in a spreadsheet computer program (Microsoft Excel 2007) and then exported to data editor page of SPSS version 15 (SPSS Inc., Chicago, Illinois, USA).

Descriptive statistics included computation of percentages, means and standard deviations. For all tests, confidence level and level of significance were set at $95 \%$ and $5 \%$ respectively.

\section{Results}

According to table number 1 Group 2 had high mean age of the study participants compared to group 1 but the comparison was non-significant. $(\mathrm{p} \leq 0.05)$ Only one patient in group A (tramadol) complained of nausea and vomiting. [Table 2]. In group A 69\% patients needed 1 rescue analgesic at $8 \mathrm{hrs}, 11 \%$ at $6 \mathrm{hrs}, 9 \%$ at $4 \mathrm{hrs}$ and $11 \%$ at $10 \mathrm{hrs}$ whereas in group B $64.1 \%$ patients needed 1 rescue analgesic at $8 \mathrm{hrs}$, $16.2 \%$ at $10 \mathrm{hrs}$ and $19.7 \%$ at12 hrs. There was a reduced consumption of intra muscular diclofenac in group B as compared to group A. There were no other significant side effects noted.

\begin{tabular}{|c|c|c|c|}
\hline Variable & $\begin{array}{l}\text { Group 1 } \\
\text { Tramadole } \\
(\text { mean } \pm \text { SD) }\end{array}$ & $\begin{array}{l}\text { Group 2 } \\
\text { Diclofenac } \\
(\text { mean } \pm S D)\end{array}$ & P value \\
\hline Age in (years) & $22.80 \pm 3.75$ & $23.85 \pm 3.45$ & 0.1 \\
\hline Weight in (kgs) & $49.21 \pm 3.01$ & $50.05 \pm 2.99$ & $0.05^{*}$ \\
\hline $\begin{array}{lr}\text { Duration } & \text { of } \\
\text { Surgery } & \text { (in } \\
\text { min) }\end{array}$ & $32.01 \pm 2.98$ & $30.22 \pm 2.10$ & 0.21 \\
\hline
\end{tabular}

Table 2: Nausea and Vomiting
\begin{tabular}{|l|l|l|l|}
\hline $\begin{array}{l}\text { Nausea and } \\
\text { Vomiting }\end{array}$ & Group A & Group B & Total \\
\hline Yes & 1 & 0 & 1 \\
\hline No & 24 & 25 & 49 \\
\hline Total & 25 & 25 & 50 \\
\hline
\end{tabular}

\section{Discussion}

Postoperative pain has been associated with grave psychological trauma causing restlessness and uncooperation in patients. ${ }^{[18]}$ Pain after laparoscopy may be due prolonged pneumoperitoneum which may be associated with tearing of blood vessels, traumatic traction on nerves and release of inflammatory mediators. ${ }^{[19]}$

Several treatment modalities are available such as local anaesthesia bilateral rectus sheath block where $15 \mathrm{ml}$ of $0.25 \%$ bupivacaine is infilterated above the umbilicus. ${ }^{[20]}$ Local anaesthetic can directly be applied on fallopian rings. ${ }^{[21]}$ Analgesic regimen should be directed in providing safe and effective analgesia with minimal side effects. NSAIDS, opioids along with dexmeditomidine are good alternatives but with dexmeditomidine there is increased incidence of somnolence and bradycardia.

After intravenous and oral administration of tramadol the absorption is rapid but it is also associated with nausea and vomiting. ${ }^{[22]}$ Rectal route is a good alternative in this regard. 
Zwaveling et al studied the pharmacokinetics of rectal tramadol and found a rectal dose of $1.5 \mathrm{mg} / \mathrm{kg}-2 \mathrm{mg} / \mathrm{kg}$ was therapeutic. ${ }^{[23]}$ Hence we had used 100mgof tramadol suppository. After administration via rectal route the absorption of active ingredient of tramadol was rapid but its metabolism quickly transformed the parent drug into high levels of $\mathrm{N}$ - desmethyl tramadol i.e M2 and N-didesmethyl tramadol i.e M5.

In group A $69 \%$ patients needed 1 rescue analgesic at $8 \mathrm{hrs,}$ $11 \%$ at $6 \mathrm{hrs}, 9 \%$ at $4 \mathrm{hrs}$ and $11 \%$ at $10 \mathrm{hrs}$ whereas in group B $64.1 \%$ patients needed 1 rescue analgesic at $8 \mathrm{hrs}, 16.2 \%$ at $10 \mathrm{hrs}$ and $19.7 \%$ at $12 \mathrm{hrs}$. Only one patient had nausea and vomiting in the tramadol group and this observation may be because of use of rectal route of administration. Zwaleing et al studied the pharmacokinetics of rectal tramadol in pediatric post operative patients and found that rectal tramadol is well absorbed with low variability in absorptions and clearance. In our study we noted that tramdol suppository administered rectally was well absorbed with longer duration of action as compared to intravenous or intramuscular route. Viitare et al, conducted a study to compare the analgesia of tramadol $2 \mathrm{mg} / \mathrm{kg}$ intravenously with the placebo group in day care adenoidectomy in pediatric patients. They concluded that less number of patients needed analgesia after discharge in tramadol group. In our study the analgesic duration and efficacy of diclofenac sodium was longer than tramadol suppository but the difference was statistically not significant. Our results are consistent with the study of $\mathrm{H}$. Gadani et al who compared rectal tramadol with intravenous tramadol in post tonsillectomy patients and concluded that rectal tramadol has longer duration of action without any gastric complication.

\section{Conclusion}

From above findings it was concluded that analgesic efficacy of tramadol and diclofenac sodium suppository is comparable. Rectal administration of tramadol reduces the incidence of nausea and vomiting. Hence intraopertive administration of tramadol suppository is a good alternative to diclofenac suppository for postoperative analgesia in laproscopic tubal ligation patients.

\section{References}

1. Joint Commission on Accreditation of Healthcare Organizations (JCAHO). National Pharmaceutical Council (NPC). Pain: current understanding of assessment, management, and treatments. Reston: NPC; 2001 .

2. Korner H, Sondenaa K, Soreide JA, Andersen E, Nysted A, Lende TH, et al. Incidence of acute nonperforated and perforated appendicitis: agespecific and sex-specific analysis. World J Surg. 1997;21(3):313-7.
3. Addiss DG, Shaffer N, Fowler BS, Tauxe RV. The epidemiology of appendicitis and appendectomy in the United States. Am J Epidemiol. 1990;132(5):910-25.

4. Korner H, Soreide JA, Pedersen EJ, Bru T, Sondenaa K, Vatten L. Stability in incidence of acute appendicitis. A population-based longitudinal study. Dig Surg. 2001;18(1):61-6.

5. Almeida OJ, Val-Gallas JM, Rizk B. Appendectomy under local anesthesia following conscious pain mapping with microlaparoscopy. Hum Reprod. 1998;13(3):588-90.

6. Lowenstein L, Zimmer EZ, Deutsch M, Paz Y, Yaniv D, Jakobi P. Preoperative analgesia with local lidocaine infiltration for abdominal hysterectomy pain management. Eur J Obstet Gynecol Reprod Biol. 2008;136(2):239-42.

7. Cheever KH. Pain, analgesic use, and morbidity in appendectomy patients. Clin Nurs Res. 1999;8(3):267-82.

8. Radbruch L, Grond S, Lehmann KA. A risk-benefit assessment of tramadol in the management of pain. Drug Saf. 1996;15(1):8-29.

9. Robert K. Stoelting, Simon C. Hillier. Pharmacology and physiology in anesthetic practice, fourth edition. Opioid agonists and antagonists, page $87-126$.

10. Lee CR, Mc Tavish D, Sorkin EM. Tramadol: A preliminary review of its pharmacodynamic and pharmacokinetic properties and therapeutic potential in acute and chronic pain states. Drugs. 1993;46:313-40.

11. Raffa RB, Friderichs E, Reimann W, Shank RP, Codd EE, Vaught JL Opioid and nonopioid components independently contribute to the mechanism of action of tramadol. An atypical opioid analgesic. J Pharmacol Exp Ther. 1992;260:275-85.

12. Pang WW, Wu HS, Lin CH, Chang DP, Huang MH. Metoclopramide decreases emesis but increases sedation in tramadol patient-controlled analgesia. Can J Anaesth. 2002;49(10):1029-33.

13. Scott LJ, Perry CM. Tramadol: a review of its use in perioperative pain. Drugs. 2000;60(1):139-76.

14. Altunkaya H, Ozer Y, Kargi E, Ozkocak I, Hosnuter M, Demirel CB, et al. The postoperative analgesic effect of tramadol when used as subcutaneous local anesthetic. Anesth Analg. 2004;99(5):1461-4.

15. M. Lotfalizade, N. Zirak et al. Comparison of effects of diclofenac suppository and tramadol injection and combination of these two drugs on pain after spinal anesthesia for cesarean. Iranian Journal of Obstetrics, Gynecology and Infertility. Dec. 2015;17(131):1-5.

16. Hina N. Gadani, Virendra Pratap Chaudhary. Comparative study of the analgesic efficacy of rectal tramadol versus intravenous tramadol for adult tonsillectomy. Anesth Essays Res. 2010 July- Dec;4(2):102-105.

17. Dr. Joshi V.S. et al. Comparative study of analgesic efficacy of rectal suppository of tramadol versus diclofenac in suppressing postoperative pain after Cesarean section. International $\mathrm{J}$. of Healthcare and Biomedical Research. January 2013, Volume: 2, P 32-37.

18. Bone ME, Fell D. comparison of rectal diclofenac with intramuscular papaveretum or placebo for pain relief after tonsillectomy. Anaesthesia1988; 43: 277-80

19. Schoeffler P etal . Coelioscopie ambulatoire. Cahiersd' Anaesthesiologie 1993;41: 385-391.

20. Smith BE etal. rectus sheath block for diagnostic laproscopy. Anaesthesia 1988; 43: 947-48.

21. Smith BE etal.rectus sheath and mesosalpinx block for laproscopic sterilization. Anaesthesia 1991;46:875-877

22. Dr. vyankatesh Joshi S etal. Comparitive study of analgesic efficacy of rectal suppository of tramadol versus diclofenac in suppressing postoperative pain after cesarean section. Internationall journal of healyhcare and biomedical research, vol 1; issue :2 jan 2013:32-33

23. J. Zwalling etal. pharmacokinetics of rectal tramadol in postoperative paediatric patients. BJA 93(2): 224-7(2004)

Copyright: () the author(s), publisher. Academia Anesthesiologica International is an Official Publication of "Society for Health Care \& Research Development". It is an open-access article distributed under the terms of the Creative Commons Attribution Non-Commercial License, which permits unrestricted non-commercial use, distribution, and reproduction in any medium, provided the original work is properly cited.

How to cite this article: Baranda UK, Baranda SK, Chaudhary M. Comparative Assessment of the Analgesic Efficacy of Tramadol and Diclofenac Sodium Rectal Suppository in Subjects Undergoing Laproscopic Tubal Ligation. Acad. Anesthesiol. Int. 2019;4(1):97-99.

DOI: dx.doi.org/10.21276/aan.2019.4.1.22

Source of Support: Nil, Conflict of Interest: None declared. 